\title{
Transition from an M1 to a mixed neuroinflammatory phenotype increases amyloid deposition in APP/PS1 transgenic mice
}

\author{
Erica M Weekman ${ }^{1,2}$, Tiffany L Sudduth ${ }^{1,2}$, Erin L Abner ${ }^{1,3}$, Gabriel J Popa ${ }^{4}$, Michael D Mendenhall, \\ Holly M Brothers ${ }^{1}$, Kaitlyn Braun ${ }^{1,2}$, Abigail Greenstein ${ }^{1}$ and Donna M Wilcock ${ }^{1,2^{*}}$
}

\begin{abstract}
Background: The polarization to different neuroinflammatory phenotypes has been described in early Alzheimer's disease, yet the impact of these phenotypes on amyloid-beta (Aß) pathology remains unknown. Short-term studies show that induction of an $\mathrm{M} 1$ neuroinflammatory phenotype reduces $A \beta$, but long-term studies have not been performed that track the neuroinflammatory phenotype.

Methods: Wild-type and APP/PS1 transgenic mice aged 3 to 4 months received a bilateral intracranial injection of adeno-associated viral (AAV) vectors expressing IFNY or green fluorescent protein in the frontal cortex and hippocampus. Mice were sacrificed 4 or 6 months post-injection. ELISA measurements were used for IFNy protein levels and biochemical levels of $A \beta$. The neuroinflammatory phenotype was determined through quantitative PCR. Microglia, astrocytes, and A $\beta$ levels were assessed with immunohistochemistry.

Results: AAV expressing IFNy induced an M1 neuroinflammatory phenotype at 4 months and a mixed phenotype along with an increase in $A \beta$ at 6 months. Microglial staining was increased at 6 months and astrocyte staining was decreased at 4 and 6 months in mice receiving AAV expressing IFNY.

Conclusions: Expression of IFNy through AAV successfully induced an M1 phenotype at 4 months that transitioned to a mixed phenotype by 6 months. This transition also appeared with an increase in amyloid burden suggesting that a mixed phenotype, or enhanced expression of $\mathrm{M} 2 \mathrm{a}$ and $\mathrm{M} 2 \mathrm{c}$ markers, could contribute to increasing amyloid burden and disease progression.
\end{abstract}

Keywords: Inflammation, Alzheimer's disease, Microglia, Beta-amyloid

\section{Background}

First described by Alois Alzheimer in 1907, Alzheimer's disease $(\mathrm{AD})$ is a progressive, neurodegenerative disease characterized pathologically by the presence of amyloid plaques formed by amyloid-beta $(A \beta)$ peptide aggregates and neurofibrillary tangles composed of hyperphosphorylated and aggregated tau protein [1]. Alois Alzheimer also described inflammation in the form of microglia surrounding amyloid plaques. Numerous studies have shown that microglial activation results from a reaction to $A \beta$ in

\footnotetext{
* Correspondence: donna.wilcock@uky.edu

'Sanders-Brown Center on Aging, University of Kentucky, Lexington, KY 40536, USA

2Department of Physiology, University of Kentucky, Lexington, KY 40536, USA Full list of author information is available at the end of the article
}

$\mathrm{AD}$ [2-5]. The overall role of neuroinflammation in $\mathrm{AD}$ remains relatively unknown.

Peripheral macrophages have been extensively characterized and shown to have distinct phenotypes dependent on their stimuli. The M1 phenotype, or classical activation, is associated with defense and attack and induces the release of pro-inflammatory cytokines such as IL-1 $\beta$, TNF $\alpha$, IL-12 and IL-6 [6,7]. The M2 phenotypes are termed alternative activation and include the M2a, M2b and M2c states. The M2a phenotype is characterized by wound healing and high levels of arginase 1 (ARG1) and the chitinase-like protein YM1 [8]. The M2b phenotype is a combination of an M1 and M2a state and is associated with high levels of CD86 and the Fc gamma receptors 1 and 3 (FcyR1 and Fc $\gamma$ R3) [8]. Finally, the M2c phenotype 
is a deactivation state accompanied by high levels of transforming growth factor beta and sphingosine kinase $1[6,9]$. It has more recently been shown that microglia are also capable of expressing most, if not all, of these inflammatory mediators under the correct conditions.

The interferon family of cytokines has been shown to be increased in human AD tissue and in the APP/PS1 mouse model, and IFN $\gamma$ is the main stimulant for microglia to produce an M1 phenotype by binding its receptor, increasing STAT1 $\alpha$, and increasing transcription of several M1 cytokine genes [10,11]. Some studies have used IFN $\gamma$ to induce an M1 phenotype, with one study showing that classical activation of microglia produces a decrease and another reporting an increase in amyloid burden $[12,13]$. Other studies have shown that inducing an M1 neuroinflammatory phenotype by introducing TNF $\alpha$, IL-1 $\beta$, or lipopolysaccharide (LPS) into the brain lowers amyloid burden [14-17]. However, these studies do not measure or track the different neuroinflammatory phenotypes along with the changes in amyloid burden over long periods of time. Additionally, engaging the immune system in the brain using anti-A $\beta$ immunotherapy has been shown to be extremely efficacious in lowering amyloid load $[18,19]$.

In order to better understand the long-term effects of an M1 neuroinflammatory phenotype we bilaterally injected an adeno-associated viral (AAV) vector expressing IFN $\gamma$ into the frontal cortex and hippocampus of wildtype and APP/PS1 mice to induce an M1 phenotype and determine the effects on $A \beta$ levels at 4 and 6 months after injection. We found that IFN $\gamma$ induced an M1 phenotype at 4 months but transitioned to include an M2 phenotype by 6 months. The transition from an M1 to a mixed phenotype did not ameliorate $\mathrm{A} \beta$ levels at 6 months. Instead, $A \beta$ levels were significantly higher, suggesting that a mixed phenotype could accelerate the disease process.

\section{Methods}

Animals

Female and male wild-type (WT) and APP/PS1 transgenic mice (C57BL6 mice carrying human APPSwe and PS1dE9 mutations) [20] were bred in house and aged for 3 to 4 months. Mice were randomly placed into one of eight groups based on AAV serotype 8 (AAV-8) injection, genotype and survival. Fifteen WT mice were assigned to receive either AAV-8 expressing green fluorescent protein (GFP) (GFP-AAV) for 4 months ( $\mathrm{n}=2$ females, 1 male) or 6 months ( $\mathrm{n}=3$ females, 3 males), or AAV-8 expressing IFN $\gamma$ (IFN $\gamma$-AAV) for 4 months $(\mathrm{n}=2$ females, 1 male) or 6 months ( $\mathrm{n}=2$ females, 1 male). Twenty APP/PS1 mice were assigned to receive either GFP-AAV for 4 months ( $n=2$ females, 2 males) or 6 months $(n=4$ females, 4 males) or IFN $\gamma$-AAV for 4 months $(n=2$ females, 1 male) or 6 months ( $\mathrm{n}=2$ females, 3 males). This study was approved by the University of Kentucky Institutional Animal Care and Use Committee and conformed to the National Institutes of Health Guide for the Care and Use of Animals in Research.

\section{Adeno-associated virus preparation}

The vector for preparing recombinant AAV was constructed by ligating the 1349 bp EcoRI/SalI fragment carrying the IRES-GFP from pSMPUW-IRES-GFP (Cell Biolabs, San Diego, CA, USA) into EcoRI/SalI-digested pZac2.1 (gift of Dr Paul Murphy, University of Kentucky) to create $\mathrm{ViCo1.28}$. The IFNy insert was prepared by PCR amplification of cDNA clones obtained from Open Biosystems (GE Healthcare, Dharmacon RNAi and gene expression, Piscataway, NJ, USA). The IFN $\gamma$ PCR primer sequence used was CCCGCTAGCTCTGAGACAATGACCACCG CGGACCCCGAATCAGCAGCGA. The Open Biosystems Catalogue number for the sequence is MMM101399829104. The clone ID is 8733812 and the accession is BC119063. The primers introduced an NheI site at the 5'-end and a SacII site at the 3'-end of the IFNY gene to facilitate cloning into the corresponding sites in ViCo1.28. The fidelity of each clone was confirmed by DNA sequence analysis.

AAV8 coat protein-pseudotyped AAV2 viruses were prepared by co-transfecting 10 T225 culture flasks of 293LTV cells (Cell Biolabs) with $250 \mu \mathrm{g}$ pAAV2/8 (obtained from the University of Pennsylvania Viral Core), $500 \mu \mathrm{g}$ pAd $\Delta$ F6 (gift of Dr Paul Murphy) and, individually, $250 \mu \mathrm{g}$ of each cytokine clone using $5 \mathrm{mg}$ polyethyleneimine to enhance DNA uptake. After 3 days, the cells were harvested, washed, suspended in $13 \mathrm{ml} 150 \mathrm{mM} \mathrm{NaCl}$, $50 \mathrm{mM}$ Tris $\cdot \mathrm{Cl} \mathrm{pH} \mathrm{8.4,} \mathrm{0.5 \%} \mathrm{deoxycholate} \mathrm{and} 50 \mathrm{U} / \mathrm{ml}$ of benzonase and incubated at $37^{\circ} \mathrm{C}$ for 30 minutes. An additional $2.8 \mathrm{ml} 5 \mathrm{M} \mathrm{NaCl}$ was added and the incubation was continued for another 30 minutes at $45^{\circ} \mathrm{C}$. The cell suspension was then subjected to four freeze/thaw cycles (30 minutes at $-80^{\circ} \mathrm{C} / 30$ minutes at $45^{\circ} \mathrm{C}$ ). The lysate was then partially clarified by centrifugation at $18,500 \times \mathrm{g}$ for 10 minutes at $20^{\circ} \mathrm{C}$. The supernatant was laid on top of an iodixanol step gradient and centrifuged at 350,000 $\times \mathrm{g}$ for 1 hour at $18^{\circ} \mathrm{C}$. The interface between the $40 \%$ and $54 \%$ iodixanol layers was withdrawn and spin-purified and concentrated using four washes with PBS in an Amicon Ultra-15 100,000 MWCO spin concentrator (Thermo Fisher, Rockford, IL)). The virus preparation was then titered using real-time PCR with primers directed against the cytomegalovirus (CMV) promoter region of the DNA encapsulated in the virions.

\section{Bilateral intracranial injection}

On the day of surgery, mice were anesthetized with isoflurane and placed into a stereotaxic apparatus (51733D digital dual manipulator mouse stereotaxic frame; Stoelting 
Co., Wood Dale, IL, USA). A midsaggital incision was used to expose the skull. Using a dental drill mounted on the stereotaxic frame, a total of four burr holes were made, one hole for each frontal cortex and hippocampus. The following coordinates were used from bregma: frontal cortex, anteroposterior, $+2.0 \mathrm{~mm}$, lateral $\pm 2.0 \mathrm{~mm}$; hippocampus, anteroposterior $-2.7 \mathrm{~mm}$, lateral $\pm 2.5 \mathrm{~mm}$. These have been previously established by the laboratory using dye injections to confirm appropriate placement. A 26 gauge needle attached to a $10 \mu \mathrm{L}$ Hamilton syringe (Hamilton, Reno, NV, USA) containing the AAV at a concentration of $2 \times 10^{9}$ genomes $/ \mu \mathrm{L}$ to be injected was lowered $3.0 \mathrm{~mm}$ ventral to bregma, and a $2 \mu \mathrm{L}$ injection was made over a 4-minute period. The incision was cleaned and sutured. Sutures were removed 2 weeks after surgery. The virus was injected at the maximum titer possible based on the concentration supplied so as to achieve the greatest expression of IFN $\gamma$.

\section{Tissue processing}

After injection with a lethal dose of Beuthanasia-D, mice were perfused intracardially with $25 \mathrm{~mL}$ normal saline. Brains were removed rapidly and bisected in the midsaggital plane. The left side of the brain was immersion fixed in $4 \%$ paraformaldehyde. The right side was dissected with the frontal cortex and hippocampus being isolated and flash frozen in liquid nitrogen and then stored at $-80^{\circ} \mathrm{C}$. The left hemibrain was passed through a series of 10,20 and $30 \%$ sucrose solutions for cryprotection. Using a sliding microtome, $25 \mu \mathrm{m}$ frozen horizontal sections were collected and stored free floating in $1 \mathrm{XDPBS}$ containing sodium azide at $4^{\circ} \mathrm{C}$.

\section{Immunohistochemistry}

Six floating sections spaced $300 \mu \mathrm{m}$ apart spanning the injection site (1800 to $3600 \mu \mathrm{m}$ ventral to bregma) were immunostained by using commercially available antibodies against $A \beta$ (Rabbit polyclonal A $\beta 1-16$, Life Technologies, Carlsbad, CA, USA), CD11b (Rat monoclonal, AbD Serotec, Raleigh, NC, USA), and glial-fibrillary acidic protein (GFAP; Rabbit polyclonal, Dako, Denmark). Immunohistochemistry was performed as previously described [21]. Briefly, sections were quenched for endogenous peroxidase, blocked and permeabalized. They were then incubated overnight in primary antibody at $4^{\circ} \mathrm{C}(\mathrm{A} \beta$ 1:3000, CD11b 1:3000, GFAP 1:10000). After washing, sections were incubated for 2 hours in the appropriate biotinylated secondary antibody (goat anti-rabbit IgG for $A \beta$ and GFAP, goat anti-rat for CD11b, all 1:3000; Vector Laboratories, Burlingame, CA, USA). Sections were then washed and incubated for 1 hour in ABC. For CD11b and GFAP, color development was performed using the DAB substrate kit with Nickel (Vector Laboratories). For A $\beta$, color development was performed using powder DAB (Sigma, St Louis, MO, USA).

Stained sections were mounted, air dried overnight, dehydrated and coverslipped in DPX (Electron Microscopy Sciences, Hatfield, PA, USA). Immunohistochemical analysis was performed by measuring percent area occupied by positive stain using the Nikon Elements BR image analysis system (Melville, NY, USA) as described previously [22].

\section{Quantitative real-time PCR}

The Trizol plus RNA purification system (Life Technologies) was used to extract RNA from the frozen right hippocampus according to the manufacturer's instructions. RNA was quantified using the Biospec nano spectrophotometer (Shimaduz, Japan). cDNA was produced using the cDNA High Capacity kit (Life Technologies) according to the manufacturer's instructions. Real-time PCR was performed using the Fast TaqMan Gene Expression assay (Life Technologies). In each well of a 96-well plate, $0.5 \mu \mathrm{L}$ cDNA (100 ng, based on the RNA concentrations) was diluted with $6.5 \mu \mathrm{L}$ RNase-free water. One microliter of the appropriate gene probe was added along with $10 \mu \mathrm{L}$ of the Fast TaqMan to each well. Target amplification was performed using ViiA7 (Applied Biosystems, Grand Island, NY, USA). The thermal cycling conditions include a holding stage at $95^{\circ} \mathrm{C}$ followed by 40 cycles of denaturation at $95^{\circ} \mathrm{C}$ for 1 second and annealing/primer extension at $60^{\circ} \mathrm{C}$ for 20 seconds. All genes were normalized to $18 \mathrm{~S}$ rRNA. We determined the fold change for mice receiving IFN $\gamma$-AAV compared with mice receiving GFP-AAV using the ${ }^{-\Delta \Delta \mathrm{Ct}}$ method [23]. Table 1 shows the genes tested along with their PMID and Taqman ID.

\section{Table 1 Genes for real-time PCR}

\begin{tabular}{lll}
\hline Gene of interest & PMID & Taqman ID \\
\hline IL-6 & NM_031168.1 & Mm00446190_m1 \\
IL-1 3 & NM_008361.3 & Mm00434228_m1 \\
IL-12a & NM_008351.2 & Mm00434165_m1 \\
IL-12b & NM_008352.2 & Mm00434174_m1 \\
ARG1 & NM_007482.3 & Mm00475988_m1 \\
YM1 (Chil3) & NM_009892.2 & Mm00657889_mH \\
CD86 & NM_019388.3 & Mm00444543_m1 \\
FCYR1 & NM_010186.5 & Mm00438874_m1 \\
FCYR3 & NM_010188.5 & Mm00438882_m1 \\
TGFB1 & NM_011577.1 & Mm01178820_m1 \\
SPHK1 & NM_011451.3 & Mm01252544_m1 \\
\hline ARG, arginas; FCyR, FC gamma
\end{tabular}

ARG, arginase; FcyR, Fc gamma receptor; IL, interleukin; SPHK, sphingosine kinase; TGF, transforming growth factor. 


\section{ELISA measurement}

Protein for $\mathrm{A} \beta$ and IFN $\gamma$ analysis was extracted from the right frontal cortex in $1 \mathrm{XDPBS}$ with complete protease and phosphatase inhibitor (Pierce Biotechnology Inc., Rockford, IL, USA). The samples were centrifuged at $10,000 \times \mathrm{g}$ at $4^{\circ} \mathrm{C}$ for 15 minutes. The supernatant was removed and labeled the "soluble" extract. The pellet was homogenized in $250 \mu \mathrm{L} 70 \%$ formic acid and centrifuged at $10,000 \times \mathrm{g}$ at $4^{\circ} \mathrm{C}$ for 1 hour. The supernatant was removed and neutralized 1:20 with $1 \mathrm{M}$ Tris $-\mathrm{HCl}$ and brought to a $\mathrm{pH}$ of 7 with $\mathrm{HCl}$. This was labeled the "insoluble" extract. Protein concentrations for the soluble and insoluble extracts were determined using the BCA protein assay kit (Pierce Biotechnology Inc.) according to the manufacturer's instructions. The MesoScale Discovery multiplex ELISA system was used to measure $A \beta 1-38, A \beta 1-40$, and $A \beta 1-42$ levels in the soluble and insoluble extracts (MSD, Gaithersburg, MD, USA). The Meso-Scale Discovery Mouse Proinflammatory 7-Plex kit (MSD) was used to measure IFNy levels in the soluble extract. All steps were followed according to the manufacturer's directions except for the sample incubation time which was left overnight.

\section{Analysis}

Data are presented as mean \pm SEM. We used two-way analysis of variance (ANOVA) based on the factors treatment (GFP-AAV or IFN $\gamma$-AAV injection) and survival time (4 or 6 months) to evaluate main effects and treatment-by-time interaction within genotype (WT and APP/ PS1). No statistical comparisons were made across genotype. Because treatment effects at each time point were of interest a priori, data are presented by treatment and time point whether or not the treatment-by-time interaction is significant.

Due to a high proportion of zero values, we used nonparametric two-way ANOVA on ranks to evaluate distributional differences in ELISA-determined IFN $\gamma$ protein levels. Similarly, we used two-way ANOVA on ranks to evaluate differences in gene expression (measured by fold change from GFP) as these data did not meet parametric ANOVA assumptions. Ranks were assigned using the RANK procedure, and ANOVA was performed using the GLM procedure in SAS/STAT 9.3 (SAS, Cary, NC, USA). Statistical significance was set at $P<0.05$.

\section{Results}

To determine that the IFN $\gamma$-AAV resulted in expression of IFN $\gamma$ we performed an ELISA measurement. Measurement of IFNY in the protein extracted from the right frontal cortex showed a significant treatment effect such that mice injected with IFN $\gamma$-AAV had a 5,000-fold increase in IFN $\gamma$ levels at 4 and 6 months in both WT and
APP/PS1 mice compared to mice receiving GFP-AAV (Figure 1).

To determine the neuroinflammatory phenotype, right hippocampal RNA was isolated and real time PCR was performed for several genes specific to an M1, M2a, M2b or M2c macrophage phenotype. Data are shown as fold change compared to GFP-AAV at each time point for each genotype. The GFP-AAV mice showed no significant change in neuroinflammation over time (data not shown). Overall, both WT and APP/PS1 mice responded to the IFN $\gamma$-AAV with a robust $\mathrm{M} 1$ response. IL-12b was increased in IFN $\gamma$-AAV treated mice at 4 and 6 months in both genotypes, and IL-1 $\beta$ was increased at all time points, except 6 months in WT (Figure 2A-D). Additionally, IL-6 and IL-12a showed significant increases at the 6-month (but not 4-month) time point in both WT and APP/PS1 mice (Figure 2B,D). At the 6-month time point, but not at the 4-month time point, M2a gene YM1 was significantly increased in WT and APP/PS1 mice (Figure 2A-D). Also of note are increased M2b markers CD86, Fc $\gamma R 1$ and $F_{c} \gamma R 3$ at the 4 and 6-month time point (Figure 2B,D). Table 2 shows the fold-change values for GFP-AAV- and IFN $\gamma$-AAV-treated mice. Interestingly, while it may appear that the APP/PS1 mice are less responsive to the IFN $\gamma$-AAV, it is actually due to the fact that APP/PS1 mice normally have an inflammatory response to the amyloid deposits in the brain and so the fold-change achieved by the IFN $\gamma$-AAV is less than in WT.

Next, assessment of CD11b immunohistochemistry in the frontal cortex (images not shown) and the hippocampus (dentate gyrus shown, Figure $3 \mathrm{~A}-\mathrm{H}$ ) was performed to determine the effect of IFNy on microglia. In all four brain regions measured, for both WT and APP/PS1 mice

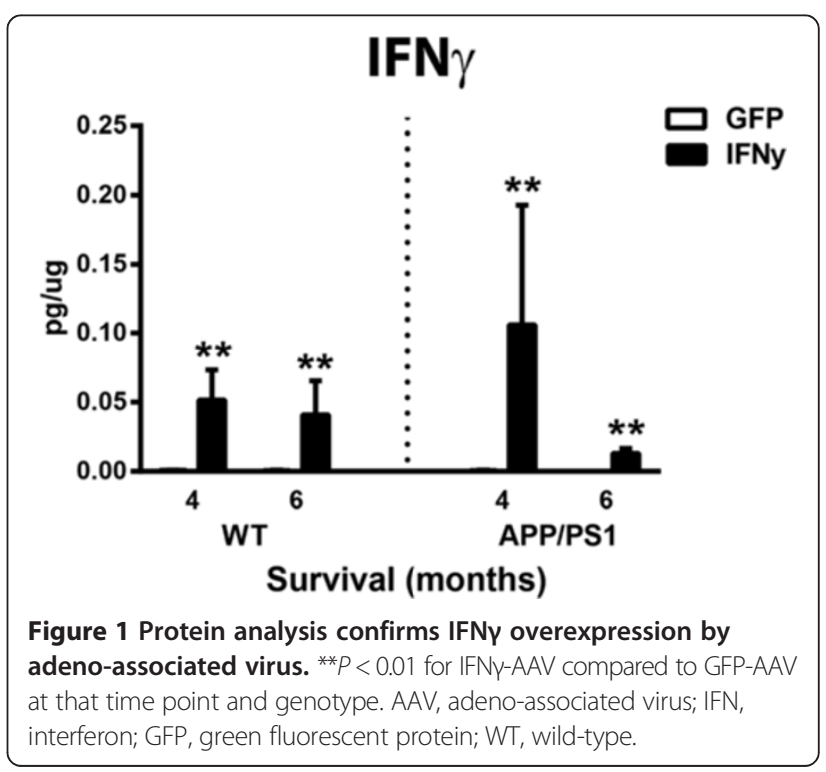



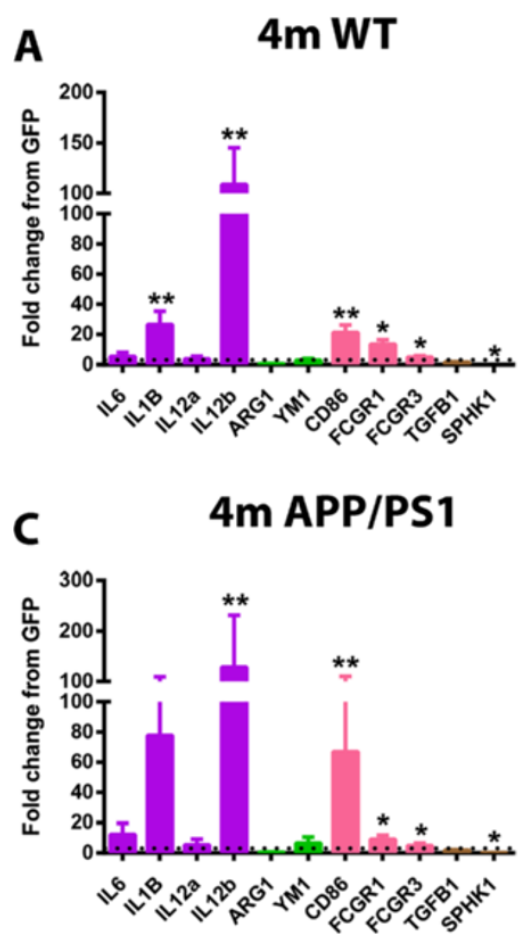

Figure 2 IFNy induces an M1 neuroinflammatory phenotype. Relative gene expression for genes representative of the M1, M2a, M2b, and M2c phenotypes. Data are shown as fold-change relative to mice receiving GFP-AAV at the given time point and genotype. (A) Wild-type (WT) mice receiving IFNY-AAV for 4 months (4 m). (B) WT mice receiving IFNY-AAV for 6 months ( 6 m). (C) APP/PS1 receiving IFNy-AAV for 4 months. (D) APP/PS1 receiving IFNY-AAV for 6 months. ${ }^{*} P<0.05$, ${ }^{*} P<0.01$, IFNY-AAV compared to GFP-AAV of that time point and genotype. \#P<0.05, $\# \# P<0.01$, 4-month IFNY-AAV compared to 6-month IFNY-AAV of that genotype. AAV, adeno-associated virus; AARG1, arginase 1; FCGR, FC gamma receptor; GFP, green fluorescent protein; IFN, interferon; IL, interleukin; SPHK1, sphingosine kinase 1; TGFB, transforming growth factor beta.

Table 2 Fold change values for real time PCR

\begin{tabular}{|c|c|c|c|c|c|c|c|c|}
\hline \multirow[b]{3}{*}{ Gene } & \multicolumn{4}{|l|}{ GFP-AAV } & \multicolumn{4}{|l|}{ IFNY-AAV } \\
\hline & \multicolumn{2}{|l|}{ WT } & \multicolumn{2}{|l|}{ APP/PS1 } & \multicolumn{2}{|l|}{ WT } & \multicolumn{2}{|l|}{ APP/PS1 } \\
\hline & $4 \mathrm{mo}$ & $6 \mathrm{mo}$ & $4 \mathrm{mo}$ & $6 \mathrm{mo}$ & $4 \mathrm{mo}$ & $6 \mathrm{mo}$ & $4 \mathrm{mo}$ & $6 \mathrm{mo}$ \\
\hline IL-6 & $1.5 \pm 0.51$ & $1.4 \pm 0.45$ & $2.46 \pm 1.36$ & $1.16 \pm 0.21$ & $5.27 \pm 2.8$ & $92.42 \pm 81.72$ & $12.23 \pm 7.43$ & $15.03 \pm 5.81$ \\
\hline $\mid L-1 \beta$ & $1.7 \pm 0.72$ & $1.2 \pm 0.27$ & $1.42 \pm 0.57$ & $1.15 \pm 0.23$ & $26.55 \pm 8.8$ & $3673.4 \pm 3599.1$ & $77.75 \pm 31.53$ & $96.07 \pm 25.74$ \\
\hline IL-12a & $1.62 \pm 0.68$ & $1.25 \pm 0.38$ & $1.75 \pm 0.79$ & $1.4 \pm 0.44$ & $3.62 \pm 1.9$ & $29.53 \pm 0.43$ & $5.37 \pm 3.92$ & $89.85 \pm 60.30$ \\
\hline IL-12b & $1.37 \pm 0.94$ & $1.29 \pm 0.39$ & $1.14 \pm 0.43$ & $1.68 \pm 0.76$ & $108.96 \pm 36.47$ & $109.55 \pm 79.82$ & $128.58 \pm 103.11$ & $239.43 \pm 77.25$ \\
\hline ARG1 & $1.95 \pm 0.79$ & $1.19 \pm 0.34$ & $1.41 \pm 0.45$ & $1.88 \pm 0.75$ & $0.55 \pm 0.09$ & $1.68 \pm 0.30$ & $0.49 \pm 0.12$ & $2.02 \pm 0.36$ \\
\hline YM1 & $1.87 \pm 1.06$ & $1.08 \pm 0.19$ & $1.31 \pm 0.51$ & $2.35 \pm 1.17$ & $2.91 \pm 1.12$ & $184.47 \pm 174.22$ & $6.48 \pm 4.07$ & $68.66 \pm 23.88$ \\
\hline CD86 & $1.21 \pm 0.3$ & $1.56 \pm 0.66$ & $1.09 \pm 0.22$ & $1.3 \pm 0.93$ & $21.2 \pm 4.97$ & $24.9 \pm 4.51$ & $66.85 \pm 43.23$ & $19.93 \pm 7.52$ \\
\hline FcyR1 & $1.2 \pm 0.28$ & $1.10 \pm 0.24$ & $1.12 \pm 0.26$ & $1.36 \pm 0.55$ & $13.45 \pm 3.05$ & $59 \pm 34.83$ & $9.11 \pm 2.61$ & $18.44 \pm 2.65$ \\
\hline FcyR3 & $1.49 \pm 0.46$ & $1.05 \pm 0.15$ & $1.14 \pm 0.31$ & $1.27 \pm 0.44$ & $4.9 \pm 0.83$ & $36.28 \pm 10.41$ & $4.89 \pm 1.61$ & $13.64 \pm 1.17$ \\
\hline TGF $\beta 1$ & $1.45 \pm 0.61$ & $1.29 \pm 0.40$ & $1.07 \pm 0.19$ & $1.23 \pm 0.26$ & $1.58 \pm 0.33$ & $3.53 \pm 0.83$ & $1.95 \pm 0.28$ & $1.95 \pm 0.74$ \\
\hline SPHK1 & $2.01 \pm 1.28$ & $1.07 \pm 0.18$ & $1.46 \pm 0.60$ & $1.58 \pm 0.77$ & $0.06 \pm 0.02$ & $8.23 \pm 2.69$ & $0.19 \pm 0.03$ & $2.21 \pm 0.28$ \\
\hline
\end{tabular}

Bold font indicates $P<0.05$ compared to GFP-AAV of that time point and genotype. AAV, adeno-associated virus; ARG1, arginase 1; FcyR, Fc gamma receptor; GFP, green fluorescent protein; IFN, interferon; IL, interleukin; mo, months; SPHK1, sphingosine kinase 1; TGF, transforming growth factor; WT, wild-type. 


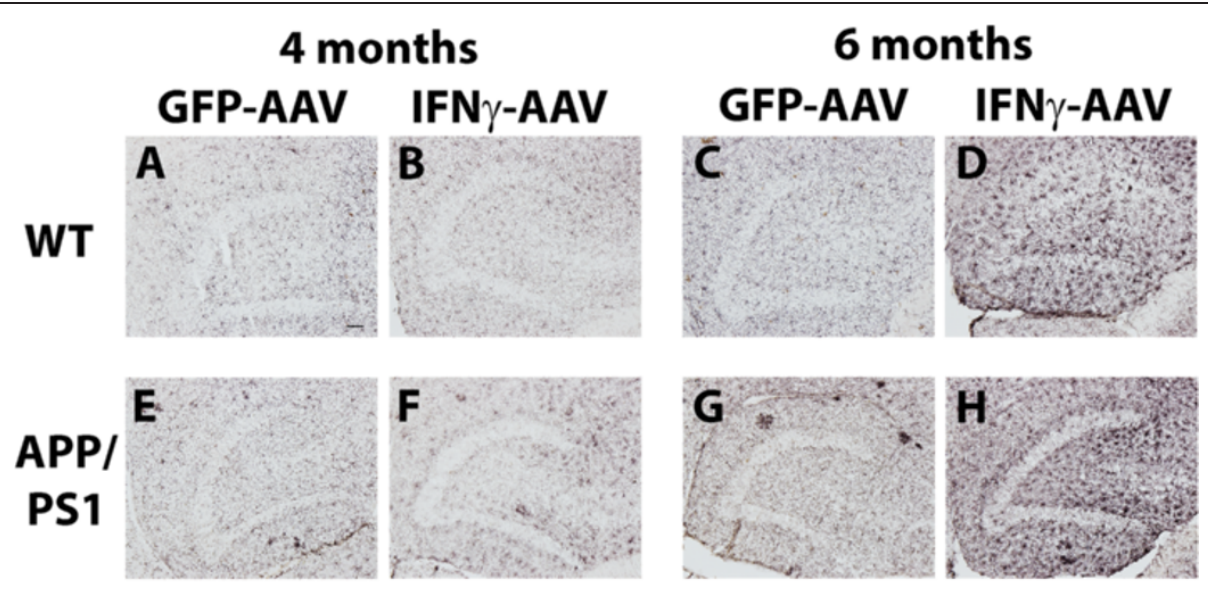

Frontal Cortex

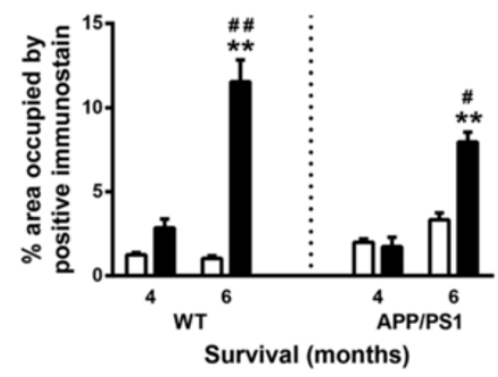

CA3

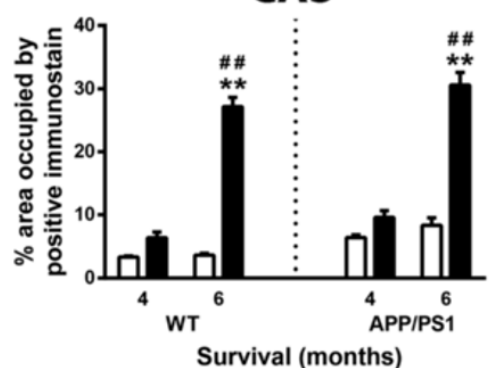

CA1

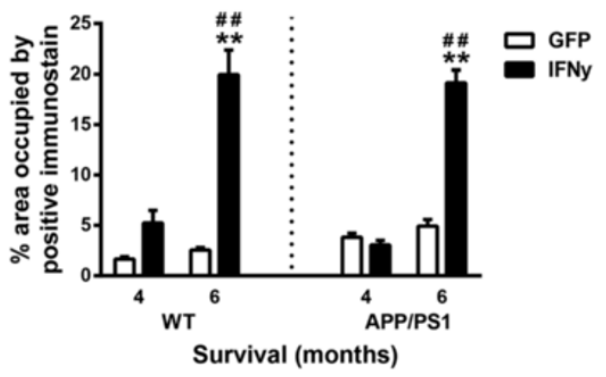

DG

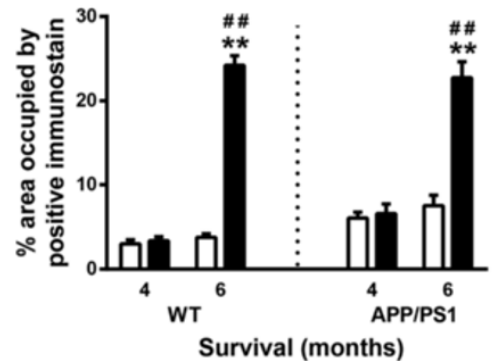

Figure 3 IFNY causes an increase in CD11b staining. (A-D) Dentate gyrus of wild-type (WT) mice receiving GFP-AAV or IFNY-AAV. (E-H) Dentate gyrus of APP/PS1 mice receiving GFP-AAV or IFNY-AAV. (I) Quantification of CD1 1b in the frontal cortex, CA1, CA3, and DG. **P $<0.01$, IFNY-AAV compared to GFP-AAV at that time point and genotype. $\# P<0.05$, \#\#P<0.01, 4-month IFNY-AAV compared to 6-month IFNY-AAV of that genotype. Scale bar in $\mathrm{A}$ is for $\mathrm{A}-\mathrm{H}$ and is equal to $50 \mu \mathrm{m}$. AAV, adeno-associated virus; DG, dentate gyrus, GFP, green fluorescent protein; IFN, interferon.

receiving IFN $\gamma$-AAV, there were statistically significant increases in CD11b staining, as measured by percent area occupied by positive immunostain, at 6 months compared to 4 months that were not observed in mice receiving GFP-AAV (that is, the treatment-by-time interaction is significant). In the frontal cortex, there was a statistically significant increase in microglial staining at 6 months but not 4 months in both WT and APP/PS1 mice injected with IFN $\gamma$-AAV compared to mice receiving GFP-AAV (Figure 3I). At 6 months in WT mice, there were significant increases in staining in the CA1, CA3 and (DG) regions (Figure 3A-D,I). APP/PS1 mice receiving IFN $\gamma$-AAV only showed modest, non-significant increases at 4 months (Figure 3E,F,I) but significant increases were observed in all hippocampal regions by 6 months (Figure 3G,H,I).

Evaluation of astrogliosis using GFAP immunohistochemistry was also performed on the frontal cortex (images not shown) and the hippocampus (dentate gyrus shown, Figure 4A-H). Distribution of GFAP staining in WT (Figure 4A,C) and APP/PS1 mice (Figure 4E,G) receiving GFP-AAV was typical for age and genotype [24]. Curiously, IFN $\gamma$-AAV injection in both the WT and APP/ PS1 mice resulted in decreased GFAP-positive staining. We found significantly decreased GFAP staining 4 months 


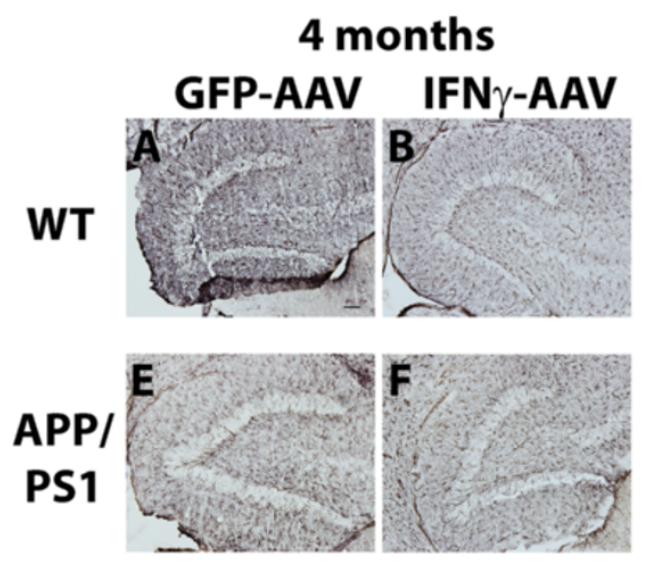

I
Frontal Cortex

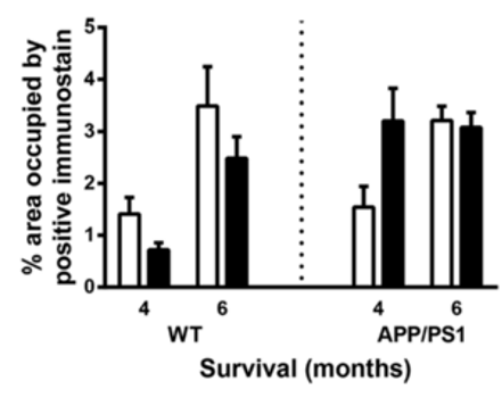

CA3

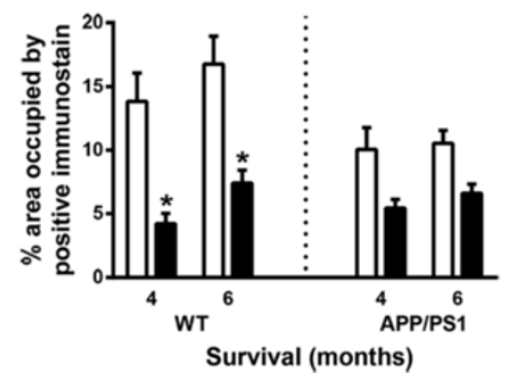

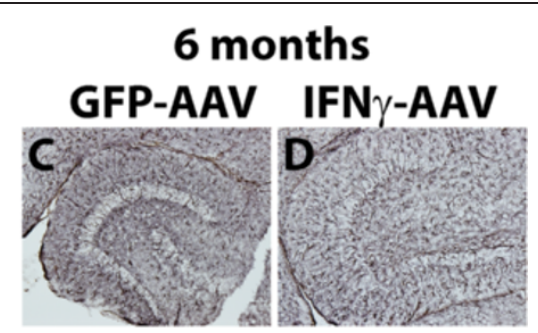

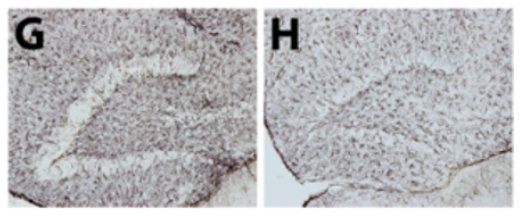

CA1

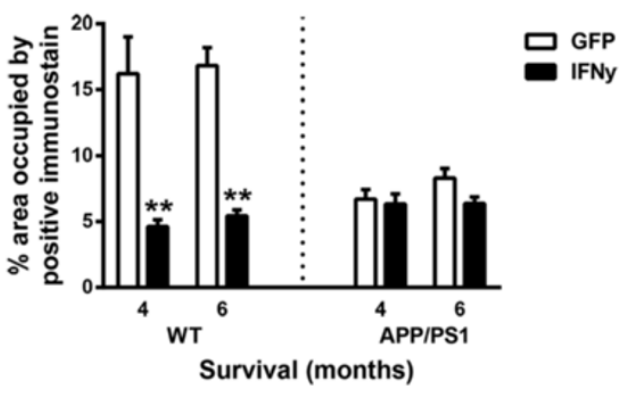

DG

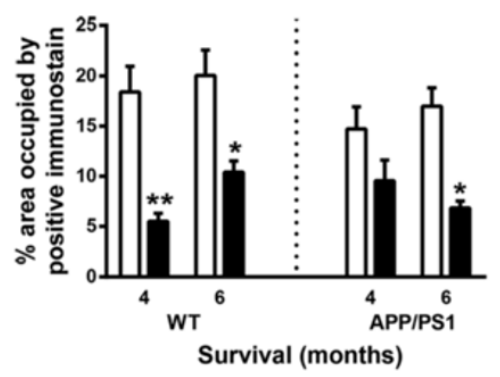

Figure 4 IFNY causes a decrease in GFAP staining. (A-D) Dentate gyrus of wild-type (WT) mice receiving GFP-AAV or IFNY-AAV. (E-H) Hippocampus of APP/PS1 mice receiving GFP-AAV or IFNY-AAV. (I) Quantification of GFAP in the frontal cortex, CA1, CA3, and DG. ${ }^{*} P<0.05$, $* * P<0.01$, IFNY-AAV compared to GFP-AAV at that time point and genotype. Scale bar in A is for A-H and is equal to $50 \mu \mathrm{m}$. AAV, adeno-associated virus; DG, dentate gyrus; GFAP, glial fibrillary acidic protein; GFP, green fluorescent protein; IFN, interferon.

after IFN $\gamma$-AAV injection in the CA1, CA3, and DG regions of WT mice (Figure 4A,B,I) There were no significant changes in GFAP staining in the CA1, CA3, or DG regions in the APP/PS1 mice at 4 months (Figure 4E,F,I). At 6 months, there was a significant decrease in astrocyte staining in the CA1, CA3 and DG regions in WT (Figure 4C,D,I) and in the DG in APP/PS1 mice (Figure 4G,H,I).

Finally, we examined the effect of IFN $\gamma$-AAV on $A \beta$ levels in the APP/PS1 mice. A $\beta$ levels were determined by immunohistochemistry and ELISA analysis. A $\beta$ deposition in the GFP-AAV mice showed a typical distribution of
APP/PS1 mice at this age both 4 and 6 months postinjection (Figure 5A,C). Immunohistochemical analysis of the frontal cortex (images not shown) and the hippocampus (DG shown, Figure 5A-D) shows no significant change in $\mathrm{A} \beta$ deposition 4 months post-injection (Figure 5A,B,E) but, at 6 months post-injection, IFN $\gamma$ $A A V$ resulted in increased $A \beta$ deposition in the frontal cortex, CA1 and CA3 regions versus GFP-AAV treated mice. A $\beta$ deposition was elevated significantly at 6 months compared to levels at 4 months in mice receiving IFN $\gamma$ AAV in all areas except the DG, where the effect was marginally significant (Figure 5B,D,E). 


\section{GFP-AAV}

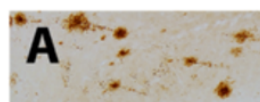

\section{4 months}

\section{6 months}

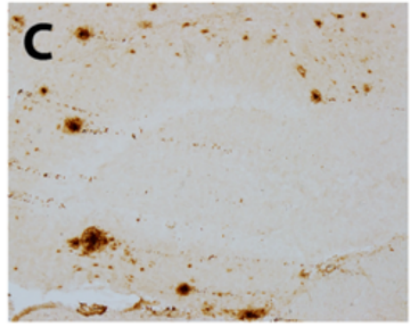

\section{IFN $\gamma$-AAV}
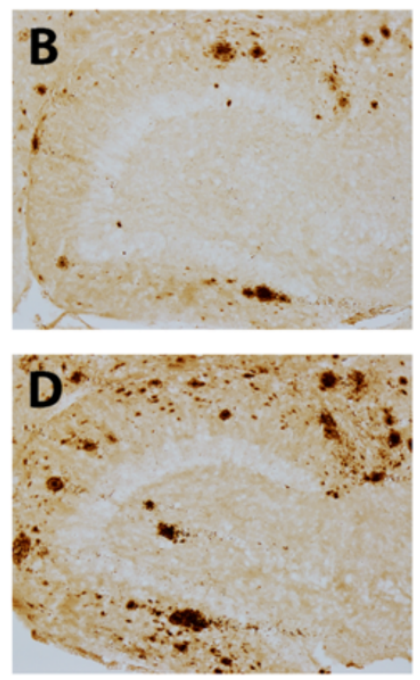

E

Frontal Cortex

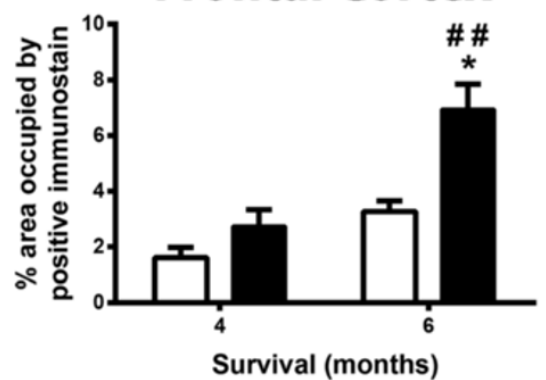

CA3
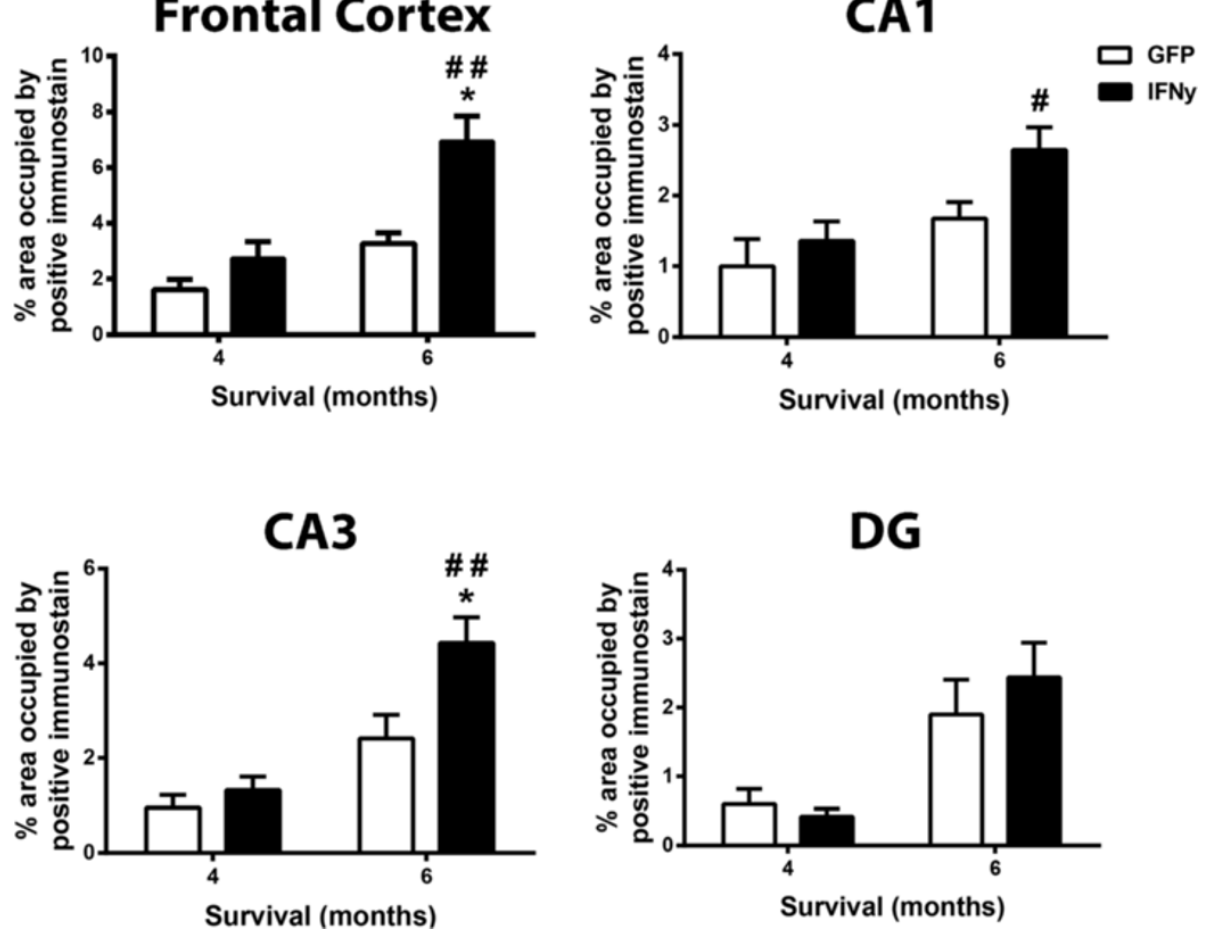

DG

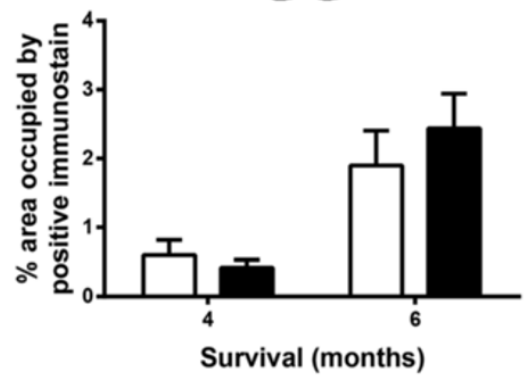

Figure 5 IFNY increases $A \beta$ deposition. (A-D) Dentate gyrus of APP/PS1 mice receiving GFP-AAV or IFNY-AAV. (E) Quantification of A 3 in the frontal cortex, CA1, CA3, and DG. ${ }^{*} P<0.05$, IFNY-AAV compared to GFP-AAV at that time point and genotype. $\# P<0.05, \# P<0.01,4-$ month IFNY-AAV compared to 6-month IFNY-AAV of that genotype. Scale bar in A is for A-D and is equal to $50 \mu \mathrm{m}$. A 3 , amyloid-beta; AAV, adeno-associated virus; DG, dentate gyrus; GFP, green fluorescent protein; IFN, interferon.

Biochemical detection of $\mathrm{A} \beta$ was performed on PBS soluble and insoluble (formic acid soluble) protein extracts from the left anterior cerebral cortex. A $\beta 1-38,1-40$ and 1-42 were analyzed by multiplexed ELISA analysis (Table 3). IFN $\gamma$-AAV injection significantly increased soluble A $\beta 1-40$ and marginally increased A $\beta 1-42$ levels at 4 months relative to GFP-AAV injection in APP/PS1 mice (Table 3). Soluble $A \beta 1-38, A \beta 1-40$ and $A \beta 1-42$ levels significantly increased from 4 to 6 months in both treatment groups at the same rate (that is, the treatment-by-time interactions were not significant), but treatment group differences at 6 months were not significant due to higher variability in 
Table 3 Soluble and insoluble amyloid-beta levels measured by ELISA

\begin{tabular}{|c|c|c|c|c|c|c|c|}
\hline \multirow[b]{2}{*}{ AAV injection } & \multirow[b]{2}{*}{ Survival (months) } & \multicolumn{3}{|c|}{ Soluble (pg/ug protein) } & \multicolumn{3}{|c|}{ 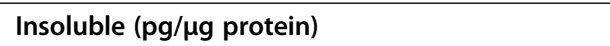 } \\
\hline & & $A \beta 1-38$ & $A \beta 1-40$ & $A \beta 1-42$ & $A \beta 1-38$ & $A \beta 1-40$ & $A \beta 1-42$ \\
\hline GFP-AAV & 4 & $1.67 \pm 0.77$ & $2.97 \pm 0.28$ & $12.90 \pm 2.24$ & $9.04 \pm 1.99$ & $98.70 \pm 36.77$ & $903.27 \pm 56.1$ \\
\hline GFP-AAV & 6 & $3.16 \pm 0.75$ & $5.10 \pm 0.44$ & $25.37 \pm 3.81$ & $23.82 \pm 2.83$ & $335.53 \pm 64.95$ & $1634.87 \pm 397.9$ \\
\hline IFNY-AAV & 4 & $3.68 \pm 0.23$ & $5.41 \pm 0.91$ & $27.17 \pm 4.94$ & $20.56 \pm 8.48$ & $295.78 \pm 87.63$ & $2855.26 \pm 1267.9$ \\
\hline IFNY-AAV & 6 & $4.95 \pm 0.51$ & $6.57 \pm 0.89$ & $38.90 \pm 7.35$ & $27.10 \pm 4.10$ & $269.72 \pm 55.2$ & $2047.32 \pm 436.0$ \\
\hline
\end{tabular}

Bold indicates $P<0.05$ compared to GFP-AAV at the same time point. A $\beta$, amyloid-beta; AAV, adeno-associated virus; ELISA, enzyme-linked immunosorbent assay; IFN, interferon.

the IFN $\gamma$-AAV treated mice. Main effects for treatment were significant for soluble $A \beta 1-38, A \beta 1-40$ and $A \beta 1-42$. No significant changes due to treatment or time were observed for insoluble $A \beta$, with the exception of $A \beta 1-38$, where there was a main effect due to time $(P=0.024)$.

\section{Discussion}

Alzheimer's disease, while characterized by amyloid plaques and neurofibrillary tangles, is associated with a robust neuroinflammatory response. Using the macrophage classification system of M1, M2a, M2b and M2c [6,7] we recently showed that the neuroinflammatory state is highly variable in the early stages of $\mathrm{AD}$ [25]. This variability was apparent in a population that was clinically and pathologically indistinguishable suggesting that neuroinflammation may be a source of variability in the Alzheimer's population. Furthermore, we hypothesize the neuroinflammatory state will influence progression of the disease and also response to therapeutic interventions. To better determine the role these distinct neuroinflammatory phenotypes have on amyloid pathology, we developed AAV vectors to express IFN $\gamma$, the initiator of an M1 neuroinflammatory state $[26,27]$, with the goal of chronically polarizing the state of the brain to an M1 state. We then injected this into the brains of APP/PS1 mice and examined their pathological progression 4 and 6 months postinjection. Overall, our data suggest that, while initially we did polarize the phenotype to M1, by 6 months the neuroinflammatory phenotype showed a combination of M1 and M2. Amyloid deposition was unaffected by the M1 phenotype but increased when the combination of inflammatory markers were increased. Whether this increase in $\mathrm{A} \beta$ is due to the M2 phenotypes direct actions or indirect actions on the M1 microglia remains unclear.

Macrophage activation can be categorized as M1, M2a, M2b and M2c. M1 is characterized by high IL-12 and low IL-10 while the M2 phenotypes are characterized by high IL-10 and low IL-12 [8]. Additionally, M1 macrophages express high levels of IL-1 $\beta$, TNF $\alpha$ and IL-6 [6]. M2a macrophages are associated with wound healing and repair gene expression including YM1 and ARG1 [8]. The M2b phenotype is very much like an M1 phenotype with the exception of the IL-10/IL-12 balance and high expression of CD86 [8]. Finally, the M2c state is characterized by high transforming growth factor beta and sphingosine kinase 1 $[6,9]$. IFN $\gamma$, with and without LPS or TNF $\alpha$, is the typical M1 phenotype stimulus [26,27]. Using BV2 microglial cell cultures, we have previously shown that treatment of BV2 cells with IFN $\gamma$ results in an M1 phenotype [28]. We hypothesized that a continuous presence of IFNy would chronically polarize the inflammatory state of the brain to an M1 state. We found that expression of IFNy through intracranial injection of IFN $\gamma$-AAV successfully induced an M1 phenotype at 4 months post-injection, but over time this transitioned to a combined M1 and M2 phenotype by 6 months. Both the early M1 phenotype and the 6 month transition to a mixed phenotype were present in both WT and APP/PS1 mice, indicating that the APP/PS1 mice and WT mice responded similarly to the IFN $\gamma$-AAV injection.

CD11b (CR3) has been used as one of a handful of microglial activation markers. In the mouse, CD11b labels ramified resting microglia, while GFAP labels astrocytes and the intensity of the staining is generally increased with inflammatory stimuli $[29,30]$. There is an assumption in the field that microglial activation and astrogliosis correspond to high levels of pro-inflammatory cytokines such as IL- $1 \beta$ and IL-6. In the current study, we find that CD11b immunostaining is not affected by the IFN $\gamma$-AAV injection at the 4-month time point, when the neuroinflammatory state is primarily M1, but is only increased when M2 markers are also increased. We also find that GFAP staining decreases when M2 markers increase even though M1 genes are still high. These data suggest that more careful analysis of neuroinflammatory markers is necessary for appropriate interpretation of data. The CD11b data here would indicate that inflammation is only increased at the 6-month time point, yet we see that at the 4-month time point IL-1 $\beta$ and IL-12 are significantly elevated.

The role of neuroinflammation on amyloid deposition remains controversial. Studies with LPS injection have shown both decreases and increases in amyloid load with neuroinflammation [15,17,31]. Additionally, microglial "activation" 
has been linked to both increased and decreased amyloid loads $[29,31]$. Our goal in this study was to determine the influence of an M1 neuroinflammatory phenotype on amyloid deposition. At the 4-month time-point, when M1 neuroinflammation predominates in the brains of mice injected with IFN $\gamma$-AAV, amyloid deposition appears unaffected with no significant difference between IFN $\gamma$-AAV and GFP-AAV injected mice. We do find increased $A \beta$ deposition at the 6-month time point, but this is in the presence of a mixed neuroinflammatory phenotype. At this time point we see not only M1 markers including IL-12, IL-1 $\beta$ and IL-6, but also the M2a marker YM1. This is not the first time that M1 markers have been associated with unchanging or decreased amyloid deposition [13]. Indeed, anti-A $\beta$ immunotherapy initiates activation of M1 markers [32]. Furthermore, we have previously shown that lithium treatment results in unchanging biochemical levels of $\mathrm{A} \beta$ but increased amyloid deposition accompanied by increased expression of M2a markers YM1, ARG1 and IL-1 receptor antagonist [22]. In this study we also see relatively unchanging biochemical levels of $A \beta$, increased $A \beta$ deposition shown by an increase in $A \beta$ staining and an increase in the expression of M2a markers at 6 months. This increase in $A \beta$ staining at 6 months implies that a mixed neuroinflammatory phenotype increases amyloid burden. While the mechanism is unclear, it appears that an M2a phenotype promotes amyloid deposition in the absence of changing total $A \beta$ levels. Future studies will attempt to elucidate the mechanism of this phenomenon.

Human data from Alzheimer's patients also shows a similar trend in neuroinflammatory switching. Our laboratory has previously shown that, in early $\mathrm{AD}$, patients are polarized towards either an M1 or an M2a phenotype [25]. By end-stage AD, patients have a combined M1, M2a and M2c phenotype. Also, early AD patients who polarized towards an M2a phenotype had an increased neuritic plaque load compared to those polarized towards an M1 phenotype. This suggests that the transition to a mixed phenotype is associated with disease progression and increased amyloid burden. Future studies on the effects of the neuroinflammatory phenotypes, especially an M2 phenotype, could provide possible therapeutic targets for $\mathrm{AD}$ progression and potential biomarkers to determine the stage of AD.

\section{Conclusions}

Expression of IFN $\gamma$ through AAV successfully induced an M1 phenotype at 4 months that transitioned to a mixed phenotype by 6 months. This transition also appeared with an increase in amyloid burden suggesting that a mixed phenotype, or enhanced expression of $\mathrm{M} 2 \mathrm{a}$ and M2c markers, could contribute to increasing amyloid burden and disease progression.

\section{Abbreviations}

A $\beta$ : amyloid-beta; AAV: adeno-associated viral; AD: Alzheimer's disease; ANOVA: analysis of variance; ARG1: arginase 1; bp: base pair; DG: dentate gyrus; ELISA: enzyme-linked immunosorbent assay; FcyR: Fc gamma receptor; GFAP: glial fibrillary acidic protein; GFP: green fluorescent protein; IFN: interferon; IL: interleukin; LPS: lipopolysaccharide; PBS: phosphate-buffered saline; PCR: polymerase chain reaction; TNF: tumor necrosis factor; WT: wild-type.

\section{Competing interests}

The authors declare they have no competing interests.

\section{Authors' contributions}

EMW performed the data collection and analysis, interpreted the data and prepared the manuscript. TLS managed the animals in the study and assisted in data collection. ELA analyzed the data. GJP and MDM developed the AAV vectors. $H M B$ assisted in revision of the manuscript. $K B$ and $A G$ assisted in tissue processing and data collection. DMW conceived of the studies, analyzed and interpreted the data, and edited the final manuscript. All authors have read and approved the final version of this manuscript.

\section{Acknowledgements}

These studies were funded by NIH grant NS079637 (DMW) and NIH grant P20GM103486 (PI: LB Hersh, pilot grant awarded to DMW), assisted by the Viral Core of the COBRE in the Molecular Basis of Human Disease (NCRR 5P20RR020171, MDM and LB Hersh, co-PIs) and by the ADC Biostatistics Core (P30AG028383). The contents of this manuscript are solely the responsibility of the authors and do not necessarily represent the official views of the $\mathrm{NIH}$, the NINDS or the NIGMS.

\section{Author details}

${ }^{1}$ Sanders-Brown Center on Aging, University of Kentucky, Lexington, KY 40536, USA. ${ }^{2}$ Department of Physiology, University of Kentucky, Lexington, KY 40536, USA. ${ }^{3}$ Department of Epidemiology, University of Kentucky, Lexington, KY 40536, USA. ${ }^{4}$ Department of Molecular and Cellular Biochemistry, University of Kentucky, Lexington, KY 40536, USA.

Received: 10 May 2014 Accepted: 22 June 2014

Published: 25 July 2014

\section{References}

1. Braak H, Braak E: Staging of Alzheimer's disease-related neurofibrillary changes. Neurobiol Aging 1995, 16:271-278. discussion 278-284.

2. Gallagher JJ, Finnegan ME, Grehan B, Dobson J, Collingwood JF, Lynch MA Modest amyloid deposition is associated with iron dysregulation, microglial activation, and oxidative stress. J Alzheimers Dis 2012, 28:147-161.

3. Maezawa I, Zimin PI, Wulff H, Jin LW: Amyloid-beta protein oligomer at low nanomolar concentrations activates microglia and induces microglial neurotoxicity. J Biol Chem 2011, 286:3693-3706.

4. Paranjape GS, Terrill SE, Gouwens LK, Ruck BM, Nichols MR: Amyloid-beta (1-42) protofibrils formed in modified artificial cerebrospinal fluid bind and activate microglia. J Neuroimmune Pharmacol 2013, 8:312-322.

5. Akiyama H, Barger S, Barnum S, Bradt B, Bauer J, Cole GM, Cooper NR, Eikelenboom P, Emmerling M, Fiebich BL, Finch CE, Frautschy S, Griffin WS, Hampel H, Hull M, Landreth G, Lue L, Mrak R, Mackenzie IR, McGeer PL, O'Banion MK, Pachter J, Pasinetti G, Plata-Salaman C, Rogers J, Rydel R, Shen Y, Streit W, Strohmeyer R, Tooyama I, et al: Inflammation and Alzheimer's disease. Neurobiol Aging 2000, 21:383-421.

6. Mosser DM, Edwards JP: Exploring the full spectrum of macrophage activation. Nat Rev Immunol 2008, 8:958-969.

7. Mantovani A, Sica A, Sozzani S, Allavena P, Vecchi A, Locati M: The chemokine system in diverse forms of macrophage activation and polarization. Trends Immunol 2004, 25:677-686.

8. Edwards JP, Zhang X, Frauwirth KA, Mosser DM: Biochemical and functional characterization of three activated macrophage populations. J Leukoc Biol 2006, 80:1298-1307.

9. Sternberg EM: Neural regulation of innate immunity: a coordinated nonspecific host response to pathogens. Nat Rev Immunol 2006, 6:318-328. 
10. Taylor JM, Minter MR, Newman AG, Zhang M, Adlard PA, Crack PJ: Type-1 interferon signaling mediates neuro-inflammatory events in models of Alzheimer's disease. Neurobiol Aging 2014, 35:1012-1023.

11. Benveniste EN, Benos DJ: TNF-alpha- and IFN-gamma-mediated signal transduction pathways: effects on glial cell gene expression and function. FASEB J 1995, 9:1577-1584.

12. Browne TC, McQuillan K, McManus RM, O'Reilly JA, Mills KH, Lynch MA: IFN-gamma production by amyloid beta-specific Th1 cells promotes microglial activation and increases plaque burden in a mouse model of Alzheimer's disease. J Immunol 2013, 190:2241-2251.

13. Chakrabarty P, Ceballos-Diaz C, Beccard A, Janus C, Dickson D, Golde TE, Das P: IFN-gamma promotes complement expression and attenuates amyloid plaque deposition in amyloid beta precursor protein transgenic mice. J Immunol 2010, 184:5333-5343.

14. Chakrabarty P, Herring A, Ceballos-Diaz C, Das P, Golde TE: Hippocampal expression of murine TNFalpha results in attenuation of amyloid deposition in vivo. Mol Neurodegeneration 2011, 6:16.

15. DiCarlo G, Wilcock D, Henderson D, Gordon M, Morgan D: Intrahippocampal LPS injections reduce Abeta load in APP + PS1 transgenic mice. Neurobiol Aging 2001, 22:1007-1012.

16. Shaftel SS, Kyrkanides S, Olschowka JA, Miller JN, Johnson RE, O'Banion MK Sustained hippocampal IL-1 beta overexpression mediates chronic neuroinflammation and ameliorates Alzheimer plaque pathology. J Clin Invest 2007, 117:1595-1604.

17. Herber DL, Roth LM, Wilson D, Wilson N, Mason JE, Morgan D, Gordon MN: Time-dependent reduction in Abeta levels after intracranial LPS administration in APP transgenic mice. Exp Neurol 2004, 190:245-253.

18. Schenk D, Barbour R, Dunn W, Gordon G, Grajeda H, Guido T, Hu K, Huang J, Johnson-Wood K, Khan K, Kholodenko D, Lee M, Liao Z, Lieberburg I, Motter R, Mutter L, Soriano D, Shopp G, Vasquez N, Vandevert C, Walker S, Wogulis M, Yednock T, Games D, Seubert P: Immunization with amyloid-beta attenuates Alzheimer-disease-like pathology in the PDAPP mouse. Nature 1999, 400:173-177.

19. Wilcock DM, DiCarlo G, Henderson D, Jackson J, Clarke K, Ugen KE, Gordon MN, Morgan D: Intracranially administered anti-Abeta antibodies reduce beta-amyloid deposition by mechanisms both independent of and associated with microglial activation. J Neurosci 2003, 23:3745-3751.

20. Jankowsky JL, Fadale DJ, Anderson J, Xu GM, Gonzales V, Jenkins NA, Copeland NG, Lee MK, Younkin LH, Wagner SL, Younkin SG, Borchelt DR: Mutant presenilins specifically elevate the levels of the 42 residue beta-amyloid peptide in vivo: evidence for augmentation of a 42-specific gamma secretase. Hum Mol Genet 2004, 13:159-170.

21. Gordon MN, Schreier WA, Ou X, Holcomb LA, Morgan DG: Exaggerated astrocyte reactivity after nigrostriatal deafferentation in the aged rat. J Comp Neurol 1997, 388:106-119.

22. Sudduth $\mathrm{TL}$, Wilson JG, Everhart A, Colton CA, Wilcock DM: Lithium treatment of APPSwDI/NOS2-/-mice leads to reduced hyperphosphorylated tau, increased amyloid deposition and altered inflammatory phenotype. PLoS One 2012, 7:e31993.

23. Livak KJ, Schmittgen TD: Analysis of relative gene expression data using real-time quantitative PCR and the 2(-Delta Delta $C(T))$ method. Methods 2001, 25:402-408.

24. Gordon MN, Holcomb LA, Jantzen PT, DiCarlo G, Wilcock D, Boyett KW, Connor K, Melachrino J, O'Callaghan JP, Morgan D: Time course of the development of Alzheimer-like pathology in the doubly transgenic PS1 + APP mouse. Exp Neurol 2002, 173:183-195.

25. Sudduth TL, Schmitt FA, Nelson PT, Wilcock DM: Neuroinflammatory phenotype in early Alzheimer's disease. Neurobiol Aging 2013, 34:1051-1059

26. Ishizuka EK, Ferreira MJ, Grund LZ, Coutinho EM, Komegae EN, Cassado AA Bortoluci KR, Lopes-Ferreira M, Lima C: Role of interplay between IL-4 and IFN-gamma in the in regulating M1 macrophage polarization induced by Nattectin. Int Immunopharmacol 2012, 14:513-522.

27. Riquelme P, Tomiuk S, Kammler A, Fandrich F, Schlitt HJ, Geissler EK, Hutchinson JA: IFN-gamma-induced iNOS expression in mouse regulatory macrophages prolongs allograft survival in fully immunocompetent recipients. Mol Ther 2013, 21:409-422.

28. Wilcock DM: A changing perspective on the role of neuroinflammation in Alzheimer's disease. Int J Alzheimer's Dis 2012, 2012:495243.
29. Frenkel D, Puckett L, Petrovic S, Xia W, Chen G, Vega J, Dembinsky-Vaknin A, Shen J, Plante M, Burt DS, Weiner HL: A nasal proteosome adjuvant activates microglia and prevents amyloid deposition. Ann Neurol 2008, 63:591-601.

30. Gonzalez-Scarano F, Baltuch G: Microglia as mediators of inflammatory and degenerative diseases. Annu Rev Neurosci 1999, 22:219-240.

31. Lee JW, Lee YK, Yuk DY, Choi DY, Ban SB, Oh KW, Hong JT: Neuro-inflammation induced by lipopolysaccharide causes cognitive impairment through enhancement of beta-amyloid generation. J Neuroinflammation 2008, 5:37.

32. Wilcock DM, Zhao Q, Morgan D, Gordon MN, Everhart A, Wilson JG, Lee JE, Colton CA: Diverse inflammatory responses in transgenic mouse models of Alzheimer's disease and the effect of immunotherapy on these responses. ASN Neuro 2011, 3:249-258.

doi:10.1186/1742-2094-11-127

Cite this article as: Weekman et al.: Transition from an M1 to a mixed neuroinflammatory phenotype increases amyloid deposition in APP/PS1 transgenic mice. Journal of Neuroinflammation 2014 11:127.

\section{Submit your next manuscript to BioMed Central and take full advantage of:}

- Convenient online submission

- Thorough peer review

- No space constraints or color figure charges

- Immediate publication on acceptance

- Inclusion in PubMed, CAS, Scopus and Google Scholar

- Research which is freely available for redistribution

Submit your manuscript at www.biomedcentral.com/submit
C BioMed Central 